\title{
A QUANTITATIVE STUDY OF NASAL BRISTLE LENGTH IN THE COMMON AND CHIHUAHUAN RAVENS
}

NATHAN PIEPLOW, 317 UCB, University of Colorado, Boulder, Colorado 80309; npieplow@gmail.com

ANDREW SPENCER, 562 Ellis Hollow Creek Rd., Ithaca, New York 14850

ABSTRACT: The proportionately longer nasal bristles of the Chihuahuan Raven (Corvus cryptoleucus) have been adduced as a character distinguishing that species from the Common Raven (C. corax). In a sample of 113 specimens of the Common Raven and 86 of the Chihuahuan we confirmed that the average of the bristle-to-bill ratio differs significantly in the two species, being $26 \%$ greater in the Chihuahuan. But the overlap is wide: only $36 \%$ of the Chihuahuan Ravens and $22 \%$ of the Common Ravens fell outside the zone of overlap. On the basis of this character, only ravens with a ratio $<0.45$ can be identified as the Common, while those with a ratio $>0.60$ are almost all Chihuahuan.

The Common Raven (Corvus corax) and Chihuahuan Raven (C. cryptoleucus) are very difficult to differentiate in the field (e.g., Leukering 2015). Although they differ markedly in size and in the basal color of the neck and breast feathers, field observations rarely allow accurate assessment of either feature.

Ridgway (1904) wrote that the Chihuahuan Raven's "nasal plumes" were longer than those of the Common Raven, and many field guides mention the length of the nasal bristles as a key field mark (Howell and Webb 1995, Dunn and Alderfer 1999, Peterson et al. 2010, Sibley 2014). In summarizing field guides and primary literature for the Birds of North America species account of the Chihuahuan Raven, Dwyer et al. (2013) indicated that the nasal bristles usually cover less than half of the bill in the Common Raven and more than half of the bill in the Chihuahuan Raven. As far as we have been able to ascertain, however, no quantitative study has ever tested the reliability of this feature in raven identification. Here we seek to address this gap.

\section{METHODS}

We measured the lengths of the culmen and nasal bristles on $113 \mathrm{Com}$ mon Ravens and 86 Chihuahuan Ravens in five museum collections. All Common Raven specimens were of the subspecies sinuatus, which ranges from southern British Columbia and Montana to Nicaragua, excluding much of California, or the subspecies clarionensis, which ranges from northern California to Baja California and western Arizona, as well as Clarión and formerly San Benedicto islands in the Revillagigedo Islands (Boarman and Heinrich 1999). These are the only two subspecies of the Common Raven regularly sympatric with, or nearly sympatric with, the Chihuahuan Raven.

We pooled all age classes for our analysis of specimens. Note, however, that previous investigators (e.g., Willett 1941) have called for better analysis 
of variation in the Common Raven that takes the age and sex classes into account. The Chihuahuan Raven specimens $(n=86)$ included 38 females, 44 males, and four individuals of unknown sex. The Common Raven specimens ( $n=113$ ) included 46 females, 59 males, and eight individuals of unknown sex.

We took measurements with either digital or analog calipers. We measured culmen length by placing one end of the calipers at the top base of the upper mandible, where the backward-pointing crown feathers meet the forward-pointing nasal bristles, forming an obvious linear "part" in the plumage perpendicular to the long axis of the bill. We then placed the other end of the calipers at the very tip of the upper mandible.

We measured bristle length by keeping one end of the calipers in place at the top base of the upper mandible and moving the other end to the tip

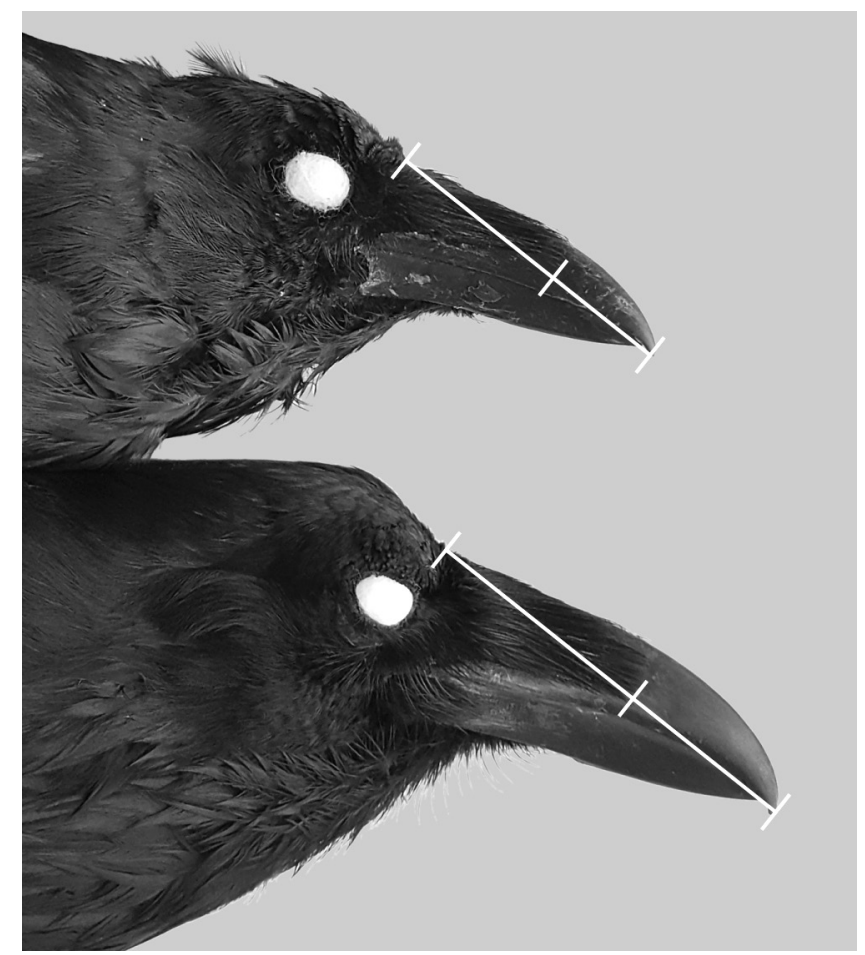

Figure 1. Specimens of the Chihuahuan Raven (top) and Common Raven (bottom) showing the measurement of culmen length from the base to the tip of the upper mandible. This Chihuahuan Raven's bristle-to-bill ratio is 0.61 , barely lower than the species' mean of 0.63 . This Common Raven's ratio is 0.57 , one standard deviation above the species' mean of 0.50 . Specimens courtesy of the Cornell University Museum of Vertebrates.

Photo by Andrew Spencer 
of the single nasal bristle that extended farthest from the top base of the upper mandible (Figure 1).

We calculated the bristle-to-bill ratio by dividing bristle length by culmen length. We used an independent-sample two-tailed $t$-test to compare bristleto-bill ratios in the two species, and we considered results significant at $\alpha=$ 0.05 . We quantified the replicability of the measurements in 22 cases in which both of us independently measured the same specimen. We used the independent measurements to calculate the bristle-to-bill ratio and then took the absolute value of the difference between the ratios. Across the 22 independently derived ratios, the average difference was 0.05 (range 0.0-0.19; SD = 0.04).

\section{RESULTS}

In the Common Ravens, culmen length averaged $67 \mathrm{~mm}$ (range 57-78; $\mathrm{SD}=4.3 ; n=113)$, and bristle length averaged $34 \mathrm{~mm}(21-45 ; \mathrm{SD}=4.7$; $n=113$ ). The bristle-to-bill ratio averaged 0.50 (range $0.34-0.66 ; \mathrm{SD}=$ $0.06 ; n=113)$.

In the Chihuahuan Ravens, culmen length averaged $54 \mathrm{~mm}$ (range 48-60; $\mathrm{SD}=2.6 ; n=86$ ), and bristle length averaged $34 \mathrm{~mm}$ (range 24-46; SD $=4.5 ; n=86)$. The Chihuahuans' bristle-to-bill ratio averaged 0.63 (range 0.45-0.81; SD $=0.08 ; n=86$ ).

The two species' bristle-to-bill ratios differed significantly $\left(t_{197}=13.70\right.$, $p<0.001$; Figure 2). Of the Common Raven specimens, $22 \%(n=25)$ had a ratio smaller than the minimum we observed in the Chihuahuan Raven (0.45), and 98\% ( $n=111$ ) had a ratio below 0.60 . Of the Chihuahuan Raven specimens, 36\% $(n=31)$ had a bristle-to-bill ratio greater than the maximum we observed in the Common Raven (0.66), and 72\% ( $n=62)$ had a ratio above 0.60 .

The bristle-to-bill ratio of males and females did not differ significantly in either the Common Raven $\left(t_{103}=1.33, p=0.19\right)$ or the Chihuahuan Raven $\left(t_{84}=0.69, p=0.49\right)$.

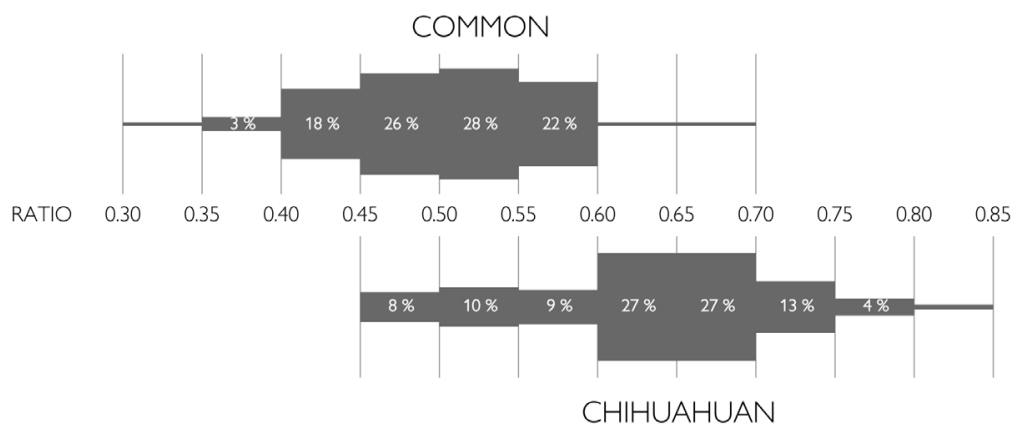

Figure 2. Histogram of bristle-to-bill ratios in the Common (top) and Chihuahuan (bottom) Ravens, by intervals of 0.05 . 


\section{DISCUSSION}

We found some overlap in culmen length between the raven species. Dwyer et al. (2013) stated, "in the hand, measurements are diagnostic: exposed culmen $\geq 65 \mathrm{~mm}$ on Common (vs. $\leq 59.0 \mathrm{~mm}$ on Chihuahuan)." Likewise, Pyle (1997) reported the exposed culmen to range from 65 to 92 $\mathrm{mm}$ in the Common Raven and from 49.5 to $59.0 \mathrm{~mm}$ in the Chihuahuan Raven. Our results differ in that $26 \%(n=29)$ of the Common Ravens in our sample had a culmen shorter than $65 \mathrm{~mm}$. These 29 specimens were all from California (subspecies clarionensis, $n=14$ ) or Utah (subspecies sinuatus, $n=15)$. Females predominated in both the specimens from California (11 females, 3 males) and from Utah (10 females, 5 males). Two of the Common Ravens in our sample (2\%) had a culmen shorter than $60 \mathrm{~mm}$, which was the maximum culmen length we measured in the Chihuahuan Raven. One such specimen was from California and one from Utah. Both were females.

Our Common Raven measurements accord with those of Boarman and Heinrich (1999), who reported an average culmen length of $65.3 \mathrm{~mm}$ in Common Ravens from Kern County, California ( $\mathrm{SD}=4.12 ; n=145$; range not reported). The lack of large Common Ravens in our sample (culmens measuring 79-92 $\mathrm{mm}$ ) presumably stems from our exclusion of the large northern subspecies principalis. As we did not distinguish between the age classes of the specimens we measured, the overlap in culmen length could be accounted for, in part, by first-year Common Ravens with the bill not yet fully grown.

Our measurements confirm prior reports (e.g., Dwyer et al. 2013) that the bristle-to-bill ratio averages significantly longer in the Chihuahuan than in the Common Raven. As the average bristle length in both species is the same $(34 \mathrm{~mm})$, the difference in ratio is primarily a function of the difference in bill length.

The Common Raven can be ruled out when the bristle-to-bill ratio is greater than 0.66 , and the Chihuahuan Raven can be ruled out when the bristle-to-bill ratio is less than 0.45 . In our sample, such definitively identifiable birds constituted $36 \%$ of the Chihuahuan Ravens $(n=31)$ and $22 \%$ of the Common Ravens $(n=25)$.

Only two of 113 Common Ravens (2\%) had a bristle-to-bill ratio of greater than 0.60 . The great majority of ravens with a ratio between 0.60 and 0.66 are Chihuahuans, but identification of such birds should be supported by other features such as size, shape, and voice.

Ravens with bristle-to-bill ratios between 0.45 and 0.60 cannot be reliably identified by bristle-to-bill ratio. In our sample, $76 \%$ of Common Ravens ( $n=$ $86)$ and $27 \%$ of Chihuahuan Ravens $(n=23)$ fell into this range of overlap.

Note that our measurements represent a chord across the curvature of the culmen from its base to the tip of the upper mandible (Figure 1). Thus, our results may differ from those derived via a measurement along the curvature of the culmen or along the horizontal length of the bill (Baldwin et al. 1931:14), which is how most field observers might be expected to estimate the bristle-to-bill ratio. Field conditions may also make it difficult to see the "part" in the feather tracts at the base of the culmen. Flying ravens, in particular, might depress their head feathers, flattening the angle between bill 
and forehead more than in perched and alert ravens. Finally, the difference between a ratio of 0.50 and a ratio of 0.60 can be quite subtle to the eye.

However, we speculate that high-quality photographs might allow an approximation of our measurement methods close enough to be useful in field identification. Photo-editing software such as Adobe Photoshop often includes "ruler" tools that allow users to measure the straight-line distance between two pixels in an image. To be useful, photographs should be taken at an angle that clearly shows the "part" in feather tracts at the base of the culmen while minimizing foreshortening of the bill in both the horizontal and vertical directions.

\section{ACKNOWLEDGMENTS}

We thank Carla Cicero, Florine Pascale, and Lelena Avila at the Museum of Vertebrate Zoology at the University of California, Berkeley; Paul R. Sweet and Lydia Garetano of the American Museum of Natural History; Jeff Stephenson and Garth Spellman of the Denver Museum of Nature and Science; Jeremiah Trimble of the Harvard Museum of Comparative Zoology; and Charles Dardia of the Cornell University Museum of Vertebrates for access to those collections. Stephanie Bilodeau and Carl Lundblad helped to locate secondary resources. We also thank Tony Leukering and James F. Dwyer for careful technical reviews.

\section{LITERATURE CITED}

Baldwin, S. P., Oberholser, H. C., and Worley, L. G. 1931. Measurements of birds. Sci. Publ. Cleveland Mus. Nat. Hist. 2:1-165.

Boarman, W. I., and Heinrich, B. 1999. Common Raven (Corvus corax), in The Birds of North America (A. F. Poole and F. B. Gill, eds)., no. 476. Birds N. Am., Inc., Philadelphia; doi.org/10.2173/bna.476.

Dunn, J. L., and Alderfer, J. (eds.) 1999. Field Guide to Birds of North America, 3rd ed. Natl. Geogr. Soc., Washington, DC.

Dwyer, J. F., Bednarz, J. C., and Raitt, R. J. 2013. Chihuahuan Raven (Corvus cryptoleucus), version 2.0, in The Birds of North America (A. F. Poole, ed)., no. 606. Cornell Lab Ornithol., Ithaca, NY; doi.org/10.2173/bna.606.

Howell, S. N. G., and Webb, S. 1995. A Guide to the Birds of México and Northern Central America. Oxford Univ. Press, Oxford, England.

Leukering, T. 2015. Ravens in Colorado: An impossible field identification? Colo. Birds 49:255-262.

Peterson, R. T., DiGiorgio, M., Lehman, P., and O'Brien, M. 2010. Peterson Field Guide to Birds of Western North America. Houghton Mifflin Harcourt, Boston.

Pyle, P. 1997. Identification Guide to North American Birds, part I: Columbidae to Ploceidae. Slate Creek Press, Bolinas, CA.

Ridgway, R. 1904. The Birds of North and Middle America. U.S. Natl. Mus. Bull. 50 , part 3.

Sibley, D. A. 2014. The Sibley Guide to Birds, 2nd ed. Knopf, New York.

Willett, G. 1941. Variation in North American ravens. Auk 58:246-249.

Accepted 13 September 2019 